In contrast, however, with this failure of equation (2), it is found that (1) is of more general application. The equetion

$$
L=a d^{2}
$$

applies with the same value of $a$ both when a steel ball is pressed into a plane lead surface and when a lead hemisphere of the same diameter is pressed on to a plane glass surface. It is found, further, that when a steel ball of diameter $D_{1}$ is pressed into a convex lead surface forming part of a sphere of diameter $D_{2}$, the same equation holds with a value of $a$ correspond. ing to that for a ball of diameter $D$ pressed into a plane surface, where

$$
\frac{1}{D}=\frac{1}{D_{1}}+\frac{1}{D_{2}}
$$

The quantity $a$ is therefore a function of the change in curvature of the deformed surface.

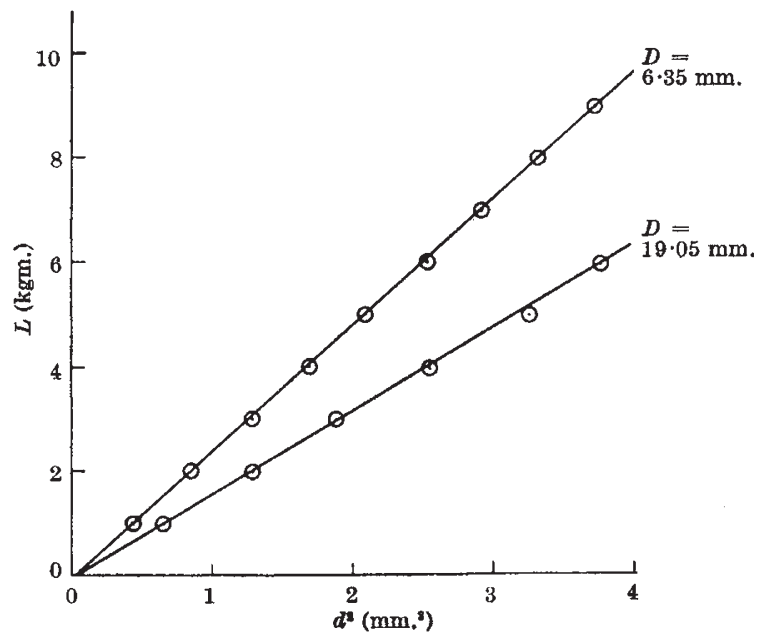

The linearity of the relationship between $L$ and $d^{2}$, and the difference in the slope of the lines for two values of $D$, is shown in the accompanying figure. The precise form of the variation of $a$ with $D$ is found to be dependent on a number of factors such as the purity of the lead (which affects its capacity for work-hardening), and the time during which the load is applied; but it is unaffected by the presence of a lubricant between the surfaces. None of these factors has been found to affect the value of $n$.

The results obtained using lead hemispheres pressed on to glass plates were remarkable in that the relations discussed above persisted even at loads so high that the diameter of the circle of contact exceeded the diameter of the original hemisphere.

Similar results were obtained using indium in place of lead.

There does not appear to be any generally known theory which will account for all the facts described.

We wish to thank the directors of Ferodo, Ltd., for permission to publish this work.

D. Натсн

E. J. W. WHITTAKER

Technical Department, Ferodo, Ltd.,

Chapel-en-le-Frith, Stockport.

$$
\text { Jan. } 12 .
$$

${ }^{1}$ Finniston, H. M., Jones, E. R. W., and Madsen, P. E., Nature, 164, $1129(1949)$

${ }^{2}$ Mayer, Z, V.D.I, 645, 750, 835 (1908)

"O'Neill, "The Hardness of Metals and its Measurcment" (London).

"Tabor, D., Proc. Roy. Soc., A, 192, 247 (1948).

\section{Anhydro-N-Carboxy-DL- $\beta$-Phenylalanine}

A. L. LEVY ${ }^{1}$ has described the preparation of anhydro-N-carboxy-DL- $\beta$-phenylalanine (II, $R=\mathrm{CH}_{2} \mathrm{Ph}$ ) by the action of phosgene on DL- $\beta$-phenylalanine. Prior to this, Fuchs ${ }^{2}$ described the preparation of anhydro-N-carboxy-N-phenyl- and N-p-tolyl-glycine by phosgenation of the parent acids in aqueous solution. Isatoic anhydride ${ }^{3}$, the analogous compound from anthranilic acid, has been similarly prepared. A modified method based on this reaction of Fuchs has been used recently by several workers in these labb. oratories. The process, which is fairly generally applicable and has been protected by a patent. application ${ }^{4}$ consists of suspending the powdered $\alpha$-amino-acid in a dry inert solvent, for example, dioxan or tetrahydrofuran, at $30^{\circ}-40^{\circ}$ and passing in gaseous phosgene with stirring until the acid is dissolved. Removal of solvent and excess phosgene by heating in vacuo at $40^{\circ}$ then affords the anhydro$\mathrm{N}$-carboxy derivative (II), the intermediate $\mathrm{N}$-substituted carbamyl chloride (I) being decomposed with the loss of hydrochloric acid during the treatment:

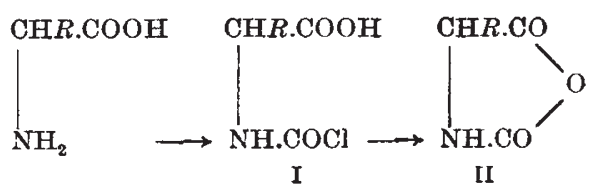

By this route it has been possible to prepare the anhydro-N-carboxy derivatives of glycine, DL- $\beta$ phenylalanine, $\alpha$-aminnisobutyric acid and L-leucine. During the preparation of the glycine derivative, the presence of N-carboxymethylcarbamyl chloride (I, $R=\mathrm{H}$ ) was shown by addition of aniline to the intermediate product, giving $\mathrm{N}$-phenylhydantoic acid.

This work, which has been carried out in connexion with research on synthetic polypeptides ${ }^{5}$, will be described in detail by D. Coleman and A. C. Farthing in forthcoming publications.

A. C. Farthing

R. J. W. REYNOLDS

Imperial Chemical Industries, Ltd.,

Research Laboratories,

Hexagon House,

Manchester 9.

Feb. 7.

1 Levy, A. L., Nature, 165, $152(1950)$

Fuchs, F., Ber., 55, 2943 (1922).

s"Org. Syntheses", 27, 45 (1947).

4 Baird, W., Parry, E. G. Robinson, S., and Imperial Chemical Industries, Itd., Brit. Pat. Appl.'20406/47 (29.7.47).

s Brown, C. J., Coleman, D., and Farthing, A. C., Nature, 163, 834 (1949).

\section{Addition of Osmium Tetroxide to Dinaphthylethylenes}

IT has been claimed by Pullman ${ }^{1}$ that the extent of conjugation of a given substituent with an aromatic ring system is determined by the electron density (index of free valence) at the position of substitution. Using the customary resonance terminology, this conclusion may be illustrated by the fact that for 1-substituted naphthalenes there are seven possible structures in which the substituent is linked to the ring by a double bond, but that for 2-substituted 